\title{
Outcome of Acute ST-Segment Elevation Myocardial Infarction in Diabetics Treated With Fibrinolytic or Combination Reduced Fibrinolytic Therapy and Platelet Glycoprotein IIb/IIIa Inhibition
}

\author{
Lessons From the GUSTO V Trial
}

Hitinder S. Gurm, MD,* A. Michael Lincoff, MD, ${ }^{*}$ David Lee, MD, ${ }^{*}$ W. H. Wilson Tang, MD,* Gang Jia, MS, ${ }^{*}$ Joan E. Booth, RN,* Robert M. Califf, MD,† E. M. Ohman, MD, $\ddagger$

Frans Van de Werf, MD, PHD,§ Paul W. Armstrong, MD,\| Victor Guetta, MD, $\uparrow$ Robert Wilcox, MD,\#

Eric J. Topol, MD*

Cleveland, Ohio; Durham and Chapel Hill, North Carolina; Leuven, Belgium; Edmonton, Canada; Tel-Hashomer, Israel; and Nottingham, United Kingdom
OBJECTIVES
We studied the outcome of diabetics enrolled in the Global Use of Strategies to Open Occluded Coronary Arteries (GUSTO) V trial to assess whether the combination of half-dose reteplase and abciximab provides any propitious benefits over standard fibrinolytic therapy in diabetic patients.
BACKGROUND Diabetics with acute ST-segment elevation myocardial infarction (MI) have a worse outcome compared with nondiabetics. Higher-risk patients are usually more likely to benefit from advances in medical therapy.
METHODS We analyzed diabetic patients enrolled in the GUSTO V trial to assess the outcome of those randomized to the combination of half-dose reteplase and abciximab versus those randomized to reteplase. We also evaluated whether any differences existed in presentation and outcome of $\mathrm{MI}$ among the diabetics versus the nondiabetics enrolled in the study.
RESULTS The trial enrolled 13,782 nondiabetics and 2,633 diabetics. Compared to nondiabetics, diabetics had a significantly higher mortality at 30 days $(8.5 \%$ vs. $5.1 \%, \mathrm{p}<0.001)$ and at 1 year $(12.7 \%$ vs. $7.5 \%, \mathrm{p}<0.001)$. Among the diabetic subset, no significant difference existed in the incidence of 30 -day $(8.8 \%$ vs. $8.2 \%, \mathrm{p}=0.52)$ or 1 -year mortality $(13.0 \%$ vs. $12.4 \%$, $\mathrm{p}=0.62)$ among patients randomized to reteplase compared to those receiving combination of abciximab and reteplase. The incidence of reinfarction $(2.5 \%$ vs. $4.3 \%, p=0.013)$, recurrent ischemia $(11.8 \%$ vs. $14.9 \%, \mathrm{p}=0.017)$, and urgent revascularization $(10.9 \%$ vs. $13.3 \%, \mathrm{p}=0.055)$ at seven days was lower in diabetics treated with the combination therapy.
CONCLUSIONS Compared to nondiabetics, diabetics continue to have a worse outcome with MI. Although combination therapy did not provide a survival benefit, nonfatal ischemic outcomes, including reinfarction, recurrent ischemia, and urgent revascularization, were substantially reduced. (J Am Coll Cardiol 2004;43:542-8) (C) 2004 by the American College of Cardiology Foundation

Diabetes is a major health problem, with over $7 \%$ of the U.S. population afflicted with the disease (1). Cardiovascular disease is the leading cause of mortality and morbidity in the diabetic population (2). Diabetes not only imparts a greater risk of myocardial infarction (MI) but is also associated with a worse short- and long-term outcome after an MI $(3,4)$.

Several encouraging pilot studies suggested earlier and

\footnotetext{
From the *Cleveland Clinic Foundation, Cleveland, Ohio; $†$ Duke Clinical Research Institute, Durham, North Carolina; ¥The University of North Carolina at Chapel Hill, North Carolina; §University Hospital Gasthuisberg, Leuven, Belgium; ॥University of Alberta, Edmonton, Canada; $\uparrow$ The Chaim Sheba Medical Center, Tel-Hashomer, Israel; and \#University Hospital Nottingham, Nottingham, United Kingdom. The GUSTO V trial was sponsored by Centocor (Malvern, Pennsylvania) and Eli Lilly (Indianapolis, Indiana).

Manuscript received May 6, 2003; revised manuscript received July 29, 2003, accepted September 8, 2003.
}

improved myocardial reperfusion in patients presenting with MI treated with combined half-dose plasminogen activator and platelet glycoprotein (GP) IIb/IIIa antagonists $(5,6)$. Diabetics have evidence of increased platelet reactivity (7-9) and appear to derive an enhanced benefit from GP IIb/IIIa platelet receptor antagonists (10-12). The Global Use of Strategies to Open Occluded Coronary Arteries (GUSTO) V was a large-scale randomized trial designed to detect a mortality difference between standard fibrinolytic therapy and the combination of reduced-dose fibrinolytic and abciximab in patients presenting with acute ST-segment elevation MI (13). Combination therapy did not significantly reduce mortality in that trial, although rates of reinfarction and urgent revascularization were significantly diminished. The objective of our study was to determine if diabetic patients 


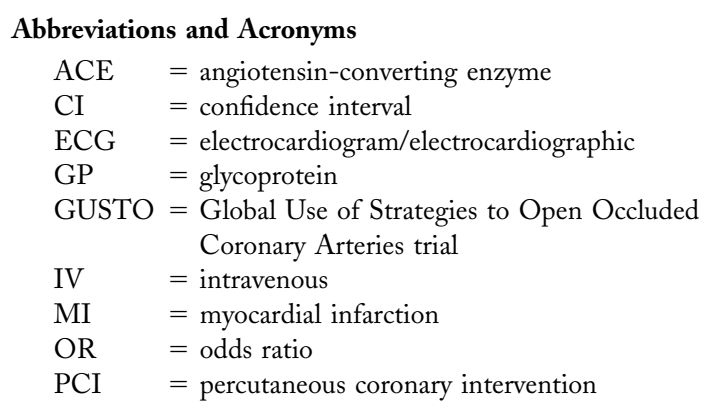

have a different pattern of benefit from combination therapy compared with nondiabetics. Furthermore, we compared the diabetic population enrolled in GUSTO V with those enrolled in the previous GUSTO I and GUSTO III trials to study the appropriate use of adjunctive therapies and outcome of diabetics over the last decade.

\section{METHODS}

The design and results of GUSTO $\mathrm{V}$ have been previously reported (13). In the GUSTO V trial, 16,588 patients with ST-segment elevation MI were randomly assigned between July 1999 and February 2001 to receive reteplase (two 10-U boluses $30 \mathrm{~min}$ apart) or the combination of abciximab (infusion of $0.25 \mathrm{mg} / \mathrm{kg}$ bolus and $0.125 \mu \mathrm{g} / \mathrm{kg} / \mathrm{min}$, [maximum of $10 \mu \mathrm{g} / \mathrm{min}$ ] infusion for $12 \mathrm{~h}$ ) plus half-dose reteplase (two boluses of $5 \mathrm{U}, 30 \mathrm{~min}$ apart). All patients were given aspirin. The participating investigator determined the use of all other adjunctive medications.

The primary end point of the GUSTO V study was all-cause mortality at 30 days. Reinfarction was defined by prolonged chest pain associated with new significant electrocardiographic (ECG) changes, an increase in cardiac enzyme concentration, or both. Recurrent ischemia was defined as symptoms lasting $>5 \mathrm{~min}, \mathrm{ECG}$ changes, and/or new hypotension, pulmonary edema or murmur, believed by the physician to represent myocardial ischemia without ECG, or enzymatic evidence of infarction. These and all other complications of acute MI were prospectively defined and recorded for all patients until day 7 or hospital discharge (whichever was earlier). Percutaneous revascularization was recorded as urgent if defined so by the investigator. Bleeding was classified as severe when associated with hemodynamic compromise, moderate when requiring transfusion without hemodynamic compromise, and mild without transfusion or hemodynamic compromise. Diabetes was defined on the basis of patient report.

The design and outcome of GUSTO I and GUSTO III trials have been previously described $(14,15)$. The GUSTO I trial randomized 41,021 patients between December 1990 and February 1993 to four different thrombolytic strategies: streptokinase and subcutaneous heparin; streptokinase and intravenous (IV) heparin; accelerated tissue plasminogen activator ( $t-P A)$ and IV heparin; or a combination of streptokinase plus t-PA with IV heparin (14). All patients received aspirin and beta-blockers (if not contraindicated), whereas use of other adjunctive medications was at the discretion of the treating physician. The GUSTO III trial randomized 15,059 patients between October 1995 and January 1997 with acute ST-elevation MI to accelerated t-PA or reteplase (15). All patients received aspirin and IV heparin. Use of all other adjunctive medications was determined by the treating physician. To compare outcome and presentation across GUSTO I, GUSTO III, and GUSTO $\mathrm{V}$ trials, we included patients from the 11 countries that were common to the three trials (Australia, Belgium, Canada, France, Germany, United Kingdom, Netherlands, Poland, Spain, Switzerland, and the U.S.).

Statistical analysis. Baseline characteristics were summarized by the use of frequencies and percentages for categorical factors and means and standard deviation for continuous factors. Differences in baseline characteristics were tested with Pearson chi-square tests for categorical factors and Wilcoxon rank-sum tests for continuous variables. Multivariable logistic models were used to estimate the adjusted odds of 30-day death for the diabetic population. Spline transformations were used for pulse rate and blood pressure and logarithmic transformation for time from symptom onset to study drug. The interactions between various variables were explored, and the significant interaction terms incorporated in the model. A value of $\mathrm{p}<0.05$ was used as the level for statistical significance. The SAS version 6.12 (SAS Inc., Cary, North Carolina) was used as the statistical software.

\section{RESULTS}

GUSTO V. The GUSTO V trial enrolled 13,782 nondiabetics and 2,633 diabetics. The baseline characteristics of the diabetics and nondiabetics are shown in Table 1 . Diabetics tended to be older and included a greater percentage of women and minorities as compared with nondiabetics. They were more likely to have hypertension, hypercholesterolemia, peripheral vascular disease, and prior history of MI and coronary revascularization. They were less likely to have a family history of premature coronary artery disease or to be current smokers. Further, diabetics were more likely to present late after onset of symptoms, to have anterior MI, and to have a higher heart rate and a worse Killip class at presentation. The 30-day mortality was significantly higher in diabetics (Table 2), and there was a trend toward a greater incidence of reinfarction. Diabetics had a significantly higher mortality at one year compared to nondiabetics $(12.7 \%$ vs. $7.5 \%, \mathrm{p}<0.001)$.

Table 3 describes the characteristics of the diabetic patients randomized to reteplase versus combination therapy. The groups were evenly matched, with a slightly greater mean age in the group randomized to combination therapy. In concordance with the overall cohort of the trial, there was 
Table 1. Baseline Characteristics of Patients Enrolled in GUSTO V Based on Diabetes

\begin{tabular}{lccc}
\hline & $\begin{array}{c}\text { Nondiabetic } \\
(\mathbf{n = 1 3 , 7 8 2})\end{array}$ & $\begin{array}{c}\text { Diabetic } \\
(\mathbf{n = 2 , 6 3 3 )}\end{array}$ & $\mathbf{p ~ V a l u e ~}$ \\
\hline Age (mean yrs) & $61 \pm 12$ & $64 \pm 11$ & $<0.001$ \\
Age $>75$ yrs & $13 \%(1,797)$ & $16 \%(422)$ & $<0.001$ \\
Female & $23.2 \%(3,193)$ & $32.2 \%(848)$ & $<0.001$ \\
Current smoker & $48.5 \%(6,631)$ & $32.1 \%(835)$ & $<0.001$ \\
Body mass index (mean) & $26.79 \pm 4.03$ & $28.38 \pm 4.72$ & $<0.001$ \\
Caucasian & $96.6 \%(13,774)$ & $93.6 \%(2,632)$ & $<0.001$ \\
Treated hypertension & $30.4 \%(4,172)$ & $51.9 \%(1,357)$ & $<0.001$ \\
Treated hypercholesterolemia & $15.2 \%(2,049)$ & $26.1 \%(658)$ & $<0.001$ \\
Family history of early CAD & $31.2 \%(3,815)$ & $27.1 \%(601)$ & $<0.001$ \\
History of PVD & $4.6 \%(582)$ & $8.3 \%(195)$ & $<0.001$ \\
Previous history of MI & $14.2 \%(1,943)$ & $20.9 \%(540)$ & $<0.001$ \\
Prior PCI & $6.2 \%(846)$ & $9.3 \%(241)$ & $<0.001$ \\
Prior CABG & $3.0 \%(415)$ & $4.9 \%(127)$ & $<0.001$ \\
Anterior MI & $36.9 \%(5,085)$ & $40.0 \%(1,052)$ & $<0.001$ \\
Mean systolic blood pressure at presentation & $134 \pm 23$ & $138 \pm 24$ & 0.01 \\
$\quad$ (mm Hg) & & & $<0.001$ \\
Mean heart rate at presentation & $74 \pm 17$ & $79 \pm 19$ & $<0.001$ \\
Killip class & & & \\
1 & $89.4 \%(12,308)$ & $83.8 \%(2,204)$ & \\
2 & $9.2 \%(1,269)$ & $13.2 \%(347)$ & \\
3 & $0.9 \%(122)$ & $2.3 \%(60)$ & \\
4 & $0.5 \%(63)$ & $0.7 \%(18)$ & \\
\hline
\end{tabular}

$\overline{\mathrm{CABG}}=$ coronary artery bypass grafting; $\mathrm{CAD}=$ coronary artery disease; $\mathrm{MI}=$ myocardial infarction; $\mathrm{PCI}=$ percutaneous coronary intervention; $\mathrm{PVD}=$ peripheral vascular disease.

no difference in the 30-day or one-year mortality among diabetics randomized to the two arms of GUSTO V (Fig. 1). A significant decrease occurred in the number of patients developing reinfarction or recurrent ischemia (Table 4) and a trend toward a decrease in the need for urgent revascularization with the combination of abciximab and half-dose reteplase. Use of combination therapy was associated with a significant reduction in the composite of death, MI, recurrent angina, or ischemia and revascularization at seven days (odds ratio [OR] 0.83, 95\% confidence interval [CI] 0.71 to $0.97, \mathrm{p}=0.021)$ and the composite of $\mathrm{MI}$, recurrent angina or ischemia and revascularization at seven days (OR 0.81, $95 \%$ CI 0.69 to $0.95, p=0.008)$. Furthermore, patients randomized to the combination therapy were overall less likely to develop complications of MI (Table 4). Although no difference was seen in the incidence of mechanical complications or heart failure, ventricular tachyarrhythmias were less likely in patients receiving the combination therapy. And even though combination therapy was associated with excess risk of bleeding, no increases in intracranial bleeding rate or blood transfusion occurred with this regimen.
Table 5 depicts the major predictors of 30-day mortality in diabetics. The model had a $c$ statistic of 0.83 , suggesting good discrimination. Four easily identifiable variables (age, heart rate, systolic blood pressure, and Killip class) provide almost $85 \%$ of the prognostic information with respect to hazard of 30-day mortality.

Compared with nondiabetics, the diabetics enrolled in GUSTO $\mathrm{V}$ were more likely to receive angiotensinconverting enzyme (ACE) inhibitors ( $67.3 \%$ vs. $56.5 \%$, p < $0.001)$, calcium channel blockers $(11.6 \%$ vs. $9.1 \%, \mathrm{p}=$ $0.001)$, digoxin ( $7.9 \%$ vs. $5.1 \%, \mathrm{p}=0.001)$, inotropic agents $(9.9 \%$ vs. $7.6 \%, \mathrm{p}=0.001)$, and nitrates $(75.3 \%$ vs. $71.6 \%$, $\mathrm{p}=0.001)$. They were less likely to receive aspirin $(93.2 \%$ vs. $94.9 \%, \mathrm{p}=0.002)$; little difference was noted in the use of beta-blockers ( $83.5 \%$ vs. $84.9 \%, p=0.116)$.

Diabetics in GUSTO I, GUSTO III, and GUSTO V. To compare outcome and adjunctive medication use among diabetics over the last decade, we compared 5,376 diabetics in GUSTO I, 1,886 in GUSTO III, and 1,938 in GUSTO V enrolled in the 11 common countries. There was a trend toward an improvement in survival across the

Table 2. Outcome of Patients Enrolled in GUSTO V Based on Diabetic Status

\begin{tabular}{lccc}
\hline & $\begin{array}{c}\text { Nondiabetic } \\
(\mathbf{n = 1 3 , 7 8 2})\end{array}$ & $\begin{array}{c}\text { Diabetic } \\
(\mathbf{n = 2 , 6 3 3 )}\end{array}$ & p Value \\
\hline Death at 30 days & $5.1 \%(709)$ & $8.5 \%(223)$ & $<0.001$ \\
Reinfarction within 7 days & $2.8 \%(385)$ & $3.4 \%(90)$ & 0.08 \\
Urgent CAGB or PCI within 7 days & $12.1 \%(1,665)$ & $12.1 \%(318)$ & 0.996 \\
$\begin{array}{l}\text { Death, MI, or urgent revascularization } \\
\quad \text { within 7 days }\end{array}$ & $16.8 \%(2,315)$ & $19.0 \%(499)$ & 0.007 \\
Death at 1 year & $7.5 \%(1027)$ & $12.7 \%(334)$ & $<0.001$ \\
\hline
\end{tabular}

Abbreviations as in Table 1. 
Table 3. Baseline Characteristics of Diabetic Patients Enrolled in GUSTO V Based on Treatment Arm

\begin{tabular}{lccc}
\hline & $\begin{array}{c}\text { Reteplase } \\
(\mathbf{n = 1 , 2 9 9 )}\end{array}$ & $\begin{array}{c}\text { Reteplase + Abciximab } \\
(\mathbf{n}=\mathbf{1 , 3 3 4})\end{array}$ & p Value \\
\hline Age (mean yrs) & $64 \pm 11$ & $65 \pm 11$ & 0.04 \\
Age $>75$ yrs & $15.8 \%(205)$ & $16.3 \%(217)$ & 0.73 \\
Female & $32.5 \%(422)$ & $31.9 \%(416)$ & 0.76 \\
Current smoker & $32.6 \%(419)$ & $31.6 \%(416)$ & 0.57 \\
Body mass index (mean) & $28.38 \pm 4.74$ & $28.38 \pm 4.70$ & 0.90 \\
Caucasian & $93 \%(1,207)$ & $94.2 \%(1,257)$ & 0.16 \\
Treated hypertension & $51.1 \%(658)$ & $52.6 \%(699)$ & 0.46 \\
Treated hypercholesterolemia & $26.4 \%(328)$ & $25.8 \%(330)$ & 0.72 \\
Family history of early CAD & $28.3 \%(312)$ & $26.0 \%(289)$ & 0.24 \\
History of PVD & $7.3 \%(84)$ & $9.4 \%(111)$ & 0.06 \\
Previous history of MI & $20.4 \%(260)$ & $21.4 \%(280)$ & 0.51 \\
Prior PCI & $9.2 \%(118)$ & $9.3 \%(123)$ & 0.91 \\
Prior CABG & $4.3 \%(55)$ & $5.4 \%(72)$ & 0.16 \\
Anterior MI & $40.5 \%(526)$ & $39.4 \%(526)$ & 0.56 \\
Mean systolic blood pressure at presentation $\quad$ & $138 \pm 24$ & $138 \pm 23$ & 0.72 \\
$\quad$ (mm Hg) & & & \\
Mean heart rate at presentation & $79 \pm 19$ & $79 \pm 19$ & 0.60 \\
Killip class & & & 0.058 \\
$\quad 1$ & & & \\
2 & & & \\
3 & $84.2 \%(1,091)$ & $13.1 \%(175)$ & \\
4 & $13.3 \%(172)$ & $2.5 \%(33)$ & \\
\hline
\end{tabular}

Abbreviations as in Table 1.

last decade (Table 6) although no improvement in survival of patients presenting in Killip class 3 and class 4 was noted. Furthermore, there was a greater utilization of appropriate adjunctive therapies in these patients, as seen in the increased use of beta-blockers and $\mathrm{ACE}$ inhibitors.

\section{DISCUSSION}

Data from the three GUSTO trials corroborate and extend previous evidence that, compared to nondiabetics, diabetics have worse outcome after MI. The large number of diabetics enrolled in GUSTO V provide a unique opportunity to study the impact of this disease on the morbidity and mortality associated with MI. Compared to nondiabetics, diabetics continue to present with a higher Killip class and have a worse outcome with MI. Although combination therapy did not provide a survival benefit, it was associated with a reduction in the incidences of reinfarction, recurrent ischemia, and urgent revascularization.

Diabetes is a rapidly growing health problem, with approximately $4 \%$ of adults being diabetics worldwide (16). The epidemic appears to be accelerating, with a projected 300 million diabetics by the year 2025 (16). Cardiovascular disease is a major cause of mortality and morbidity in diabetics, and multiple studies have suggested a markedly

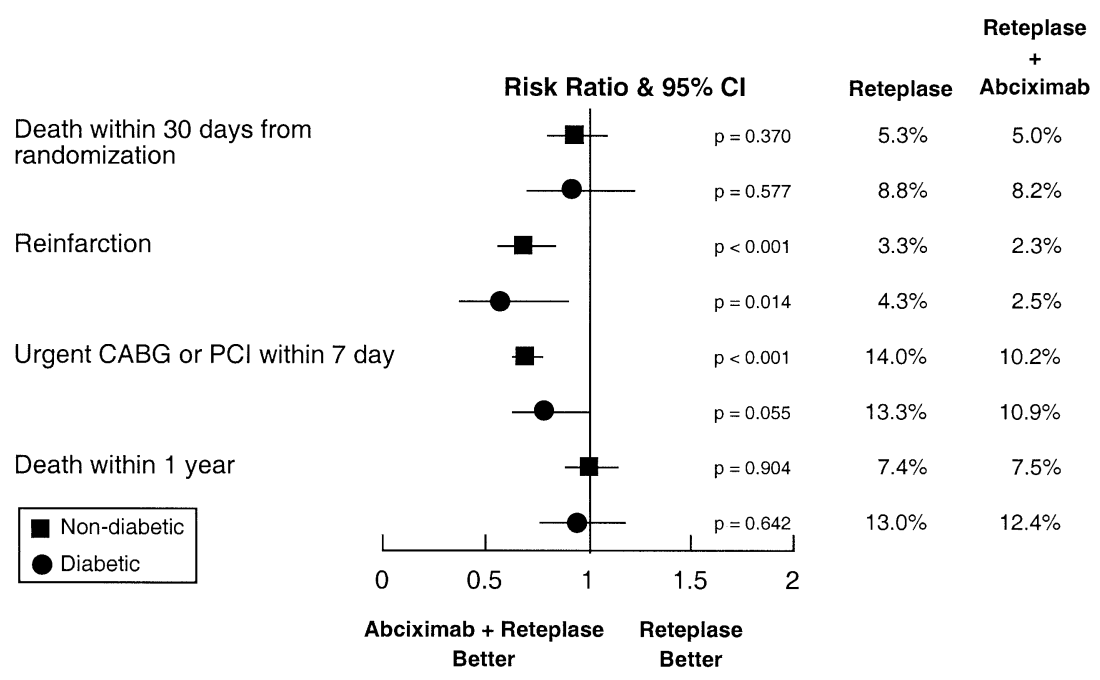

Figure 1. Outcome of diabetics with myocardial infarction randomized to standard versus combination therapy. CABG = coronary artery bypass grafting; $\mathrm{CI}=$ confidence interval; $\mathrm{PCI}=$ percutaneous coronary intervention. 
Table 4. Complications of MI and its Treatment in Diabetics Randomized to Standard Versus Combination Therapy

\begin{tabular}{lccr}
\hline & $\begin{array}{c}\text { Reteplase } \\
(\mathbf{n = 1 , 2 9 9 )}\end{array}$ & $\begin{array}{c}\text { Reteplase + Abciximab } \\
(\mathbf{n = 1 , 3 3 4 )}\end{array}$ & p Value \\
\hline Any complication of index MI & $35.8 \%(465)$ & $30.0 \%(400)$ & 0.002 \\
Reinfarction & $4.3 \%(56)$ & $2.5 \%(34)$ & 0.013 \\
Recurrent ischemia/angina & $14.9 \%(194)$ & $11.8 \%(157)$ & 0.017 \\
Composite of 7-day death, MI, recurrent & $44.99 \%(584)$ & $40.54 \%(540)$ & 0.021 \\
$\quad$ ischemia/angina or revascularization & & & \\
Composite of 7-day MI, recurrent ischemia/ & $40.76 \%(529)$ & $35.74 \%(476)$ & 0.008 \\
$\quad$ & & \\
$\quad$ New sina or revascularization & $6.6(86)$ & $7.0(93)$ & 0.721 \\
Myocardial rupture & $0.6 \%(8)$ & $0.7 \%(9)$ & 0.851 \\
Ventricular septal defect & $0.3 \%(4)$ & $0.2 \%(3)$ & 0.722 \\
Sustained ventricular tachycardia & $3.2 \%(42)$ & $1.9 \%(26)$ & 0.038 \\
Ventricular fibrillation & $3.6 \%(47)$ & $2.1 \%(28)$ & 0.019 \\
Atrial fibrillation & $5.1 \%(66)$ & $4.5 \%(60)$ & 0.483 \\
Asystole & $2.7 \%(35)$ & $3.2 \%(43)$ & 0.423 \\
2nd or 3rd degree heart block & $3.5 \%(45)$ & $2.5 \%(34)$ & 0.169 \\
Intracranial hemorrhage & $1.0 \%(13)$ & $0.6 \%(8)$ & 0.004 \\
Any bleeding & $14.2 \%(184)$ & $26.7 \%(356)$ & $<0.001$ \\
Blood transfusion & $5.5 \%(71)$ & $6.5 \%(86)$ & 0.288 \\
\hline
\end{tabular}

$\mathrm{CHF}=$ congestive heart failure; $\mathrm{MI}=$ myocardial infarction.

worse outcome in diabetics presenting with ST-segment elevation or non-ST-segment elevation MI $(3,4)$.

Recent evidence points to emergence of platelets as key mediators in acute coronary syndromes (17). Diabetics have evidence of increased platelet activation (7), adhesiveness and aggregability (8), and greater expression of platelet GP IIb/IIIa, thrombospondin, and P selectin (9). Based on these lines of evidence, potent platelet inhibition may be of particular benefit in diabetic patients presenting with acute coronary syndromes. While all subjects appeared to benefit from peri-procedural abciximab, the diabetic substudy of Evaluation of platelet IIb/IIIa inhibitor for stenting trial (EPISTENT) suggested an enhanced outcome in diabetics randomized to abciximab (11). Combined analysis from three major percutaneous coronary intervention (PCI) trials suggested a marked one-year mortality benefit of abciximab in diabetics undergoing PCI (12). Similar enhanced benefits of tirofiban in diabetics have been reported in the setting of acute coronary syndromes (18). Roffi et al. (10) performed a meta-analysis of all major trials of platelet GP IIb/IIIa inhibitors in non-ST-segment elevation acute coronary syndrome and described a reduction in 30-day mortality in diabetics from $4.0 \%$ to $1.2 \%(\mathrm{p}=0.002)$. This improved outcome in diabetics in PCI and acute coronary syndromes raises the question of possible enhanced benefit for diabetics in the setting of ST-segment elevation MI as well.

The randomized design and the large number of diabetic patients enrolled in GUSTO V provided an almost matched population in the two arms. In parallel with the main trial, no significant mortality difference was noted between patients treated with reteplase or combination therapy. However, the consistent reductions in reinfarction, recurrent ischemia, urgent revascularization, and malignant ventricular arrhythmias as seen in the main trial suggest additional benefits of enhanced platelet suppression achieved using combination therapy. Fibrinolytic agents lyse fibrinthrombin clot and release free thrombin, which is a potent stimulator of platelet aggregation (19).

Table 5. Predictors of 30-Day Mortality in Diabetics in a Multivariable Model

\begin{tabular}{lccrr}
\hline & Odds Ratio & $\mathbf{9 5 \%}$ CI & Chi-Square & p Value \\
\hline Age $(\mathrm{yrs})$ & 1.073 & $1.052-1.094$ & 49.764 & $<0.001$ \\
$\mathrm{SBP}(<115 \mathrm{~mm} \mathrm{Hg})^{*}$ & 0.969 & $0.950-0.989$ & 9.165 & 0.003 \\
$\mathrm{SBP}(\geq 115 \mathrm{~mm} \mathrm{Hg})^{*}$ & 0.972 & $0.962-0.983$ & 26.986 & $<0.001$ \\
Pulse $(<58 / \mathrm{min}) \dagger$ & 1.000 & $0.939-1.064$ & 0 & 1.000 \\
Pulse $(>58 / \mathrm{min}) \dagger$ & 1.023 & $1.014-1.032$ & 26.343 & $<0.001$ \\
Killip class III and IV & 4.638 & $2.537-8.479$ & 24.848 & $<0.001$ \\
Anterior infarct & 1.584 & $1.123-2.234$ & 6.863 & 0.009 \\
History of PVD & 1.772 & $1.088-2.887$ & 5.287 & 0.022 \\
Current smoker & 0.552 & $0.334-0.887$ & 6.029 & 0.014 \\
Weight $>90 \mathrm{~kg}$ & 0.538 & $0.327-0.884$ & 5.984 & 0.014
\end{tabular}

*Systolic blood pressure (SBP) had a varying effect on mortality hazard. Each $1 \mathrm{~mm} \mathrm{Hg}$ rise was associated with a greater proportional reduction in the hazard of mortality below an SBP of $115 \mathrm{~mm} \mathrm{Hg}$ compared to a somewhat lesser reduction in hazard above an SBP of $115 \mathrm{~mm} \mathrm{Hg}$. $\dagger$ A rising pulse was associated with an increasing hazard of mortality above a heart rate of 58. No relationship was seen between mortality and a heart rate lower than 58 .

$\mathrm{CI}=$ confidence interval; $\mathrm{PVD}=$ peripheral vascular disease. 
Table 6. Outcome and Medication Use in Diabetics in GUSTO I, GUSTO III, and GUSTO V

\begin{tabular}{lcccc}
\hline \multicolumn{1}{c}{ Diabetic Subset } & $\begin{array}{c}\text { GUSTO I } \\
\mathbf{( 1 9 9 0 - 1 9 9 3 )}\end{array}$ & $\begin{array}{c}\text { GUSTO III } \\
\mathbf{( 1 9 9 5 - 1 9 9 7 )}\end{array}$ & $\begin{array}{c}\text { GUSTO V } \\
\mathbf{( 1 9 9 9 - 2 0 0 1 )}\end{array}$ & p Value \\
\hline Diabetics/total & $5,376 / 37,110$ & $1,886 / 11,996$ & $1,938 / 12,603$ & \\
& $(14.5 \%)$ & $(15.7 \%)$ & $(15.4 \%)$ & \\
Death (30 days) & $10.7 \%$ & $10.9 \%$ & $8.9 \%$ & 0.06 \\
30 day-mortality (Killip class I and II) & $9.3 \%$ & $9.6 \%$ & $7.5 \%$ & 0.04 \\
30-day mortality (Killip class III and IV) & $44.5 \%$ & $44.1 \%$ & $50.0 \%$ & 0.722 \\
Beta-blocker use & $75.1 \%$ & $75.7 \%$ & $83.5 \%$ & $<0.001$ \\
ACE inhibitor use & $28.9 \%$ & $54.9 \%$ & $67.3 \%$ & $<0.001$ \\
Aspirin use & $98.1 \%$ & $98.6 \%$ & $93.2 \%$ & $<0.001$ \\
\hline ACE $=$ angiotensin-converting enzyme. & & & &
\end{tabular}

$\mathrm{ACE}=$ angiotensin-converting enzyme.

Combination therapy would hence be expected to specifically impact on the platelet-mediated recurrent ischemic events and distal embolization. Indeed, the current data support the previously described reduction in clinical events and improved tissue level perfusion with combination therapy $(5,20)$. These improvements in key complications of MI are at the cost of an increase in mild and moderate bleeding. However, the need for transfusions or the incidence of intracranial hemorrhage was not higher in the combination arm, hence suggesting an acceptable safety profile.

These findings are in contrast to those from the Assessment of the Safety and Efficacy of a New Thrombolytic Regimen (ASSENT)-III study (21), which suggested a worse outcome among diabetic patients receiving half-dose tenecteplase and abciximab combination therapy compared to those receiving tenecteplase and heparin. These results from ASSENT-III are probably a reflection of the small number of diabetics in that study (355 in the combination therapy arm versus 363 in the unfractionated heparin plus tenecteplase arm and 380 in the enoxaparin plus tenecteplase arm) and may exemplify a type I statistical error. Alternatively, these differences may relate to the different agents used or differences in the patients enrolled and are best delineated in an adequately powered prospective study.

Previous experience with abciximab in the setting of primary PCI for ST-segment elevation MI has been even more encouraging. The small number (53) of diabetics enrolled in the Abciximab before Direct Angioplasty and Stenting in Myocardial Infarction Regarding Acute and Long-Term Follow-up (ADMIRAL) trial who received abciximab in the setting of stenting for ST-segment elevation MI had a significant reduction in the six-month mortality rate as compared with those randomized to placebo ( $0 \%$ vs. $16.7 \%, p=0.02)(22)$. Further, a significant reduction occurred in the composite of death, reinfarction, or any revascularization. Reminiscent of the data in acute coronary syndrome, the benefit of abciximab appeared to be enhanced in diabetics compared to nondiabetics. The lack of similar findings in GUSTO V may suggest vital difference in the role of abciximab in the setting of two differing strategies of reperfusion. Whereas more evidence supports the efficacy of such therapy in primary PCI, the lack of mortality benefit with combination therapy makes its rou- tine use less compelling and suggests a need for further research to clarify its role in clinical practice.

Compared with the GUSTO I and GUSTO III trials, GUSTO V was marked by an improvement in 30-day survival after MI. This improvement was seen in both diabetics and nondiabetics and may represent temporal trends in improved therapy or differences in type of enrolled patients. A comparison of diabetics and nondiabetics suggests a worse outcome in diabetics in concordance with previous work. The key predictive variables of outcome in diabetics were similar to those in the nondiabetic population. Heart rate and blood pressure retained a major predictive role in this population despite the theoretical concerns of dysautonomia.

Concern has been raised that diabetics are less likely to receive appropriate adjunct therapy following an MI. Using the Monitoring Trends and Determinants in Cardiovascular Disease (MONICA) Augsburg registry, Lowel and colleagues (23) found marked underutilization of beta-blockers during hospitalization and at discharge in diabetics. McGuire et al. (3) also described a lower use of betablockers $(68.4 \%$ vs. $72.4 \%, \mathrm{p}=0.001)$ in diabetics compared with nondiabetics in the GUSTO-IIb study. Concerns about masking of hypoglycemia in diabetics may have been responsible in part for the underutilization of such proven therapy. In GUSTO V, diabetics and nondiabetics were equally likely to receive beta-blockers, whereas diabetics were actually more likely to receive angiotensinconverting enzyme (ACE) inhibitors, calcium channel blockers, and digoxin. This may reflect the increased awareness of benefits of ACE inhibitors in diabetics and the increased prevalence of hypertension and congestive heart failure in this group. A comparison across GUSTO I, GUSTO III, and GUSTO V shows an appropriate increase in use of beta-blockers and ACE inhibitors in diabetics. The use of aspirin decreased somewhat and could not be accounted for by increased bleeding complications, randomization arm, or use of adenosine diphosphate antagonists, the latter being used in only a small minority of aspirin nonusers (data not shown). This increased utilization of the appropriate and proven therapies may directly contribute to or may be a marker of better overall care, which in turn 
might conceivably have led to the improvement seen in outcome of diabetics in GUSTO V.

Study limitations. Our analysis was a retrospective subgroup analysis, and hence it is subject to the known limitations regarding sample size and spurious findings inherent in such work. Diabetes was defined by patient report and may have led to significant underreporting of diabetes. No data on $\mathrm{HbA}_{1 \mathrm{c}}$ or blood glucose at presentation were available. Further, time to ST-segment resolution was available only in a small number of diabetics, thus precluding study of effect of combination therapy on microvascular perfusion. The diabetic substudy was underpowered to detect a mortality difference at 30 days, although our findings parallel those of the main trial and thus are likely to be extant. These findings should be considered hypothesis generating and hence require validation in prospective studies.

Differing enrollment criteria, varying practice patterns, and evidence base and different therapeutic agents being tested limit the comparison of diabetics across the three GUSTO trials. We have accordingly limited our analysis to provide general information about use of adjunctive therapies as a barometer of practice patterns across similar centers over the last decade.

Conclusions. Diabetes continues to be associated with a worse outcome after ST-segment elevation MI, in part owing to the more serious associated co-morbidities and partly due to a worse clinical presentation. There has been an improvement in outcome and use of appropriate adjunct therapy in diabetics when compared to historical controls. As in nondiabetics, combination therapy appears to reduce the risk of recurrent ischemia, reinfarction, need for revascularization, and ventricular tachyarrhythmias in diabetics without any improvement in either short- or long-term mortality. Although the improvement in secondary end points with combination therapy provides a small step forward, the continued high short- and long-term mortality reinforces the significance of the burden associated with a common and growing public health problem.

Reprint requests and correspondence: Dr. A. Michael Lincoff, Department of Cardiovascular Medicine, Desk F25, The Cleveland Clinic Foundation, 9500 Euclid Ave., Cleveland, Ohio 44195. E-mail: lincofa@ccf.org.

\section{REFERENCES}

1. Mokdad AH, Bowman BA, Ford ES, Vinicor F, Marks JS, Koplan JP. The continuing epidemics of obesity and diabetes in the United States. JAMA 2001;286:1195-200.

2. Haffner SM, Lehto S, Ronnemaa T, Pyorala K, Laakso M. Mortality from coronary heart disease in subjects with type 2 diabetes and in nondiabetic subjects with and without prior myocardial infarction. N Engl J Med 1998;339:229-34.

3. McGuire DK, Emanuelsson $\mathrm{H}$, Granger $\mathrm{CB}$, et al.. Influence of diabetes mellitus on clinical outcomes across the spectrum of acute coronary syndromes. Findings from the GUSTO-IIb study. GUSTOIIb Investigators. Eur Heart J 2000;21:1750-8.

4. Mak KH, Moliterno DJ, Granger CB, et al.. Influence of diabetes mellitus on clinical outcome in the thrombolytic era of acute myocardial infarction. GUSTO-I Investigators. Global Utilization of Streptokinase and Tissue Plasminogen Activator for Occluded Coronary Arteries. J Am Coll Cardiol 1997;30:171-9.

5. Antman EM, Giugliano RP, Gibson CM, et al.. Abciximab facilitates the rate and extent of thrombolysis: results of the Thrombolysis in Myocardial Infarction (TIMI) 14 trial. The TIMI 14 Investigators. Circulation 1999;99:2720-32.

6. Brener SJ, Zeymer U, Adgey AA, et al.. Eptifibatide and low-dose tissue plasminogen activator in acute myocardial infarction: the Integrilin and low-dose Thrombolysis in Acute Myocardial Infarction (INTRO AMI) trial. J Am Coll Cardiol 2002;39:377-86.

7. Davi G, Catalano I, Averna M, et al.. Thromboxane biosynthesis and platelet function in type II diabetes mellitus. N Engl J Med 1990;322: 1769-74.

8. Knobler H, Savion N, Shenkman B, Kotev-Emeth S, Varon D. Shear-induced platelet adhesion and aggregation on subendothelium are increased in diabetic patients. Thromb Res 1998;90:181-90.

9. Tschoepe D, Rauch U, Schwippert B. Platelet-leukocyte-cross-talk in diabetes mellitus. Horm Metab Res 1997;29:631-5.

10. Roffi M, Chew DP, Mukherjee D, et al.. Platelet glycoprotein IIb/IIIa inhibitors reduce mortality in diabetic patients with non-ST-segmentelevation acute coronary syndromes. Circulation 2001;104:2767-71.

11. Marso SP, Lincoff AM, Ellis SG, et al.. Optimizing the percutaneous interventional outcomes for patients with diabetes mellitus: results of the EPISTENT (Evaluation of Platelet IIb/IIIa Inhibitor for Stenting Trial) diabetic substudy. Circulation 1999;100:2477-84.

12. Bhatt DL, Marso SP, Lincoff AM, Wolski KE, Ellis SG, Topol EJ. Abciximab reduces mortality in diabetics following percutaneous coronary intervention. J Am Coll Cardiol 2000;35:922-8.

13. Topol EJ. Reperfusion therapy for acute myocardial infarction with fibrinolytic therapy or combination reduced fibrinolytic therapy and platelet glycoprotein IIb/IIIa inhibition: the GUSTO V randomised trial. Lancet 2001;357:1905-14.

14. The GUSTO Investigators. GUSTO-I. An international randomized trial comparing four thrombolytic strategies for acute myocardial infarction. N Engl J Med 1993;329:673-82.

15. The GUSTO-III investigators. A comparison of reteplase with alteplase for acute myocardial infarction. The Global Use of Strategies to Open Occluded Coronary Arteries (GUSTO III). N Engl J Med 1997;337:1118-23.

16. King H, Aubert RE, Herman WH. Global burden of diabetes, 1995-2025: prevalence, numerical estimates, and projections. Diabetes Care 1998;21:1414-31.

17. Topol EJ. Toward a new frontier in myocardial reperfusion therapy: emerging platelet preeminence. Circulation 1998;97:211-8.

18. Theroux P, Alexander J Jr., Pharand C, et al.. Glycoprotein IIb/IIIa receptor blockade improves outcomes in diabetic patients presenting with unstable angina/non-ST-elevation myocardial infarction: results from the Platelet Receptor Inhibition in Ischemic Syndrome Management in Patients Limited by Unstable Signs and Symptoms (PRISMPLUS) study. Circulation 2000;102:2466-72.

19. Becker RC. Reocclusion following successful thrombolysis. Emerging concepts. Cardiology 1993;82:265-73.

20. The SPEED Investigators. Trial of abciximab with and without low-dose reteplase for acute myocardial infarction. Strategies for Patency Enhancement in the Emergency Department (SPEED) group. Circulation 2000;101:2788-94.

21. The ASSENT-III Investigators. Efficacy and safety of tenecteplase in combination with enoxaparin, abciximab, or unfractionated heparin: the ASSENT-3 randomised trial in acute myocardial infarction. Lancet 2001;358:605-13.

22. Montalescot G, Barragan P, Wittenberg O, et al.. Platelet glycoprotein IIb/IIIa inhibition with coronary stenting for acute myocardial infarction. N Eng1 J Med 2001;344:1895-903.

23. Lowel H, Koenig W, Engel S, Hormann A, Keil U. The impact of diabetes mellitus on survival after myocardial infarction: can it be modified by drug treatment? Results of a population-based myocardial infarction register follow-up study. Diabetologia 2000;43: $218-26$. 